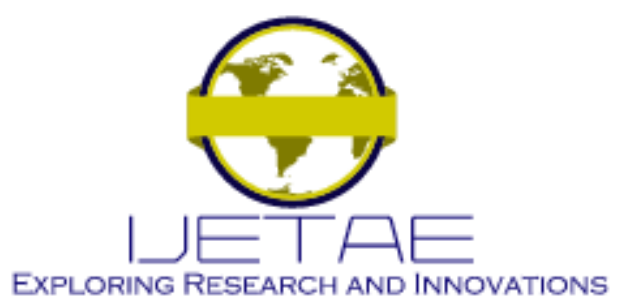

International Journal of Emerging Technology and Advanced Engineering

Website: www.ijetae.com (E-ISSN 2250-2459, Scopus Indexed, ISO 9001:2008 Certified Journal, Volume 11, Issue 09, September 2021)

\title{
Design of a Thermal Imaging System to Detect Possible Cases of COVID-19 Patients
}

\author{
Luis Nuñez-Tapia ${ }^{1}$, Brian Meneses-Claudio ${ }^{2}$, Witman Alvarado-Díaz ${ }^{3}$ \\ ${ }^{1,2,3}$ Universidad de Ciencias y Humanidades \& Av. Universitaria 5175, Los Olivos
}

\begin{abstract}
The problem that the world is currently facing and that has claimed more than $\mathbf{3 . 2}$ million lives worldwide is COVID-19. Being a highly contagious disease, the WHO recommended limiting the movement of people out of their residence. Given this, Peru took the necessary measures to control the spread of this virus, therefore, the government decreed a general quarantine in the country, which from March $6^{\text {th }}$ to May $9^{\text {th }}, 2020$, had reported the death of 1814 people in the country, because the health system at the national level was not prepared for such magnitude, in addition to that the number of infections continued to grow since they do not respect social distancing. In view of this problem, this article will design a thermal image processing system to detect possible cases of patients with COVID-19, in such a way that it allows companies or institutions to know the body temperature of each person, and thus know they are possibly COVID-19 patients. Through the design of this system, it will be possible to measure body temperature with the drone and the thermal camera at $50 \mathrm{~cm}$ from the person, in such a way that if the person has a body temperature higher than $38^{\circ} \mathrm{C}$ it could be infected with COVID-19. Therefore, the implementation of this system will help reduce the number of infections within an institution or workplace.
\end{abstract}

Keywords-- Thermal camera, COVID-19, Drone, MATLAB, Image.

\section{INTRODUCTION}

COVID-19 is a highly transmissible and pathogenic viral infection caused by severe acute respiratory syndrome coronavirus 2 (SARS-CoV-2) [1], which being a highly contagious disease has spread rapidly throughout the world and has been announced as a pandemic by the World Health Organization (WHO) [2]. It originated in the city of Wuhan and is the cause of a large number of cases and deaths in China and in increasing numbers outside of it, becoming a public health emergency worldwide [3].
In this context, WHO recommended limiting transfers to places outside their residence to avoid a possible spread [4]; With these recommendations, the governments established a mandatory social isolation for all citizens, in such a way that the number of infections that has caused an unprecedented devastation in the health of the world population can be reduced, infecting more than 153 million people up to on May $1^{\text {st }}, 2021$ and claiming more than 3.2 million lives worldwide [5].

In Peru, the situation was not so alien, the first case was reported in Lima on March $6^{\text {th }}, 2020$ [6], so on March $16^{\text {th }}$, 2020 the government decreed a general quarantine throughout the country, closing the borders with the aim of combating the pandemic, which with the passing of the days the quarantine was extending due to the fact that there was no decrease in the number of infections. The measures taken by the government were a bit late, since the WHO declared it a global pandemic on March $11^{\text {th }}, 2020$ [5] and that from March $6^{\text {th }}$ to May $9^{\text {th }}, 2020$ in the country it had already been reported the death of 1814 people [4]. Being a new virus, the symptoms that people who contract it were unknown, later it was determined that it produces symptoms like those of the flu, which include fever, cough, dyspnea, myalgia, and fatigue. Sudden loss of smell and taste (without mucus being the cause) has also been observed [7]. The doctor Ciro Maguiña Vargas mentioned that this new disease (COVID-19) has uncovered, in a crude and real way, the terrible health situation in Peru [8]. Faced with these problems faced by the health system at the national level, different measures have been taken, such as teleworking, on the other hand, people have chosen to clean and disinfect objects and surfaces that are frequently touched. Also, an important factor is the specific physical distance (1 or 2 meters) between individuals to reduce the transmission of SARS-CoV-2, since the virus that causes COVID-19, is based on an outdated and dichotomous notion of respiratory droplet size [9]. 


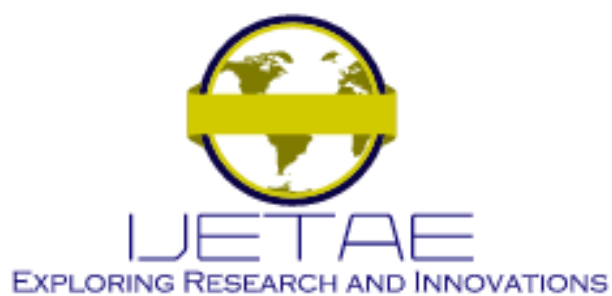

International Journal of Emerging Technology and Advanced Engineering

Website: www.ijetae.com (E-ISSN 2250-2459, Scopus Indexed, ISO 9001:2008 Certified Journal, Volume 11, Issue 09, September 2021)

The objective of the research work is to design a thermal image processing system to detect possible cases of patients with COVID-19, in such a way that it allows companies or institutions to know the body temperature of each worker, and thus know if they are infected, this system will be very useful to reduce the number of infections within a workplace. For the elaboration of the design, a drone was used that will take photos with a thermal camera of different people and that, through the image processing developed in MATLAB, indicates the body temperature. The MATLAB mathematical software allows us to perform numerical calculations with vectors and matrices and is very useful for image processing since it allows us to manipulate images.

In section II, the literature review will mention previous research work. In section III, the methodology will indicate the electronic part and the system design. In section IV, the results generated according to the tests performed with the system design will be presented. In section $\mathrm{V}$, the discussion will be presented, where the importance of the present work with respect to other works carried out will be indicated. Finally, in section VI, the conclusion and recommendation obtained from the system design will be presented.

\section{LITERATURE REVIEW}

At first glance, it is not known which person has COVID19 , for this it is necessary to carry out a test or medical study. Therefore, it is necessary to maintain the corresponding distance with other people, for this, it can use a system that, through captured images, can detect if social distancing is fulfilled. For example: In [10], the authors identified that the exponential increase in the number of COVID-19 infections is mainly due to the fact that the measure of social distancing recommended by medical and scientific communities is not being met, which is why they proposed to carry out a pilot test through the processing to video images for the detection of people in open spaces in the downtown area of the city of Cúcuta, Colombia. The proposed method consists of the analysis of information from videos of people with a static background, taken from a height of 4.5 meters, in addition to the location of centroids by the moment method and distance estimation by the Euclidean method, through programming language Python. Obtaining as a result a success in the detection of people was $92.43 \%$, concluding that $84.21 \%$ of those who circulated through the video frame and transit in the downtown area of the city of Cúcuta, Colombia, fail to comply with the recommended social distancing of two meters by the scientific community.
In [11], the authors identified that people do not respect social distancing, so the government needs to monitor the movement and interaction of people, because the COVID19 outbreak spreads through community interaction between people, especially in densely populated areas, therefore, the government needs a crowd surveillance system that can detect the presence of people, identify the crowd and give warnings of social distancing, that is why they proposed to design the surveillance system of COVID19 social distancing in an effective, efficient and safe way, thus using road segmentation in the IRIS PX4 drone in the Robots Operating System and the Gazebo simulation that together with the algorithm to detect people or objects YOLO-v3, define a social distancing detector. Obtaining as a result an efficiency of detection of people and crowds located around $90 \%$, concluding that drones can also be equipped with thermal sensors so that the COVID-19 inspection can be identified.

Finally, in [12], the authors identified that, to reduce the number of infections in workers within their workplace, it is necessary to measure the body temperature of each worker, because a common symptom of COVID-19 is fever and that if he or she has a high body temperature he or she could be infected, that is why they proposed a system for detecting employee fever with the thermal camera integrated in the attendance management system, thus using a thermal camera, which has a heat sensor and can detect any temperature difference, even with a hot cup of coffee it will not go wrong and will give accurate results. Obtaining as a result an efficiency of $99.78 \%$, since when the thermal camera detects a body temperature lower than $99^{\circ} \mathrm{F}\left(37^{\circ} \mathrm{C}\right)$ it gives the green light, otherwise it is not allowed to enter at workplace, concluding that there are some limitations like camera accuracy and situations like an infected person not showing the highest temperature or an uninfected person showing the temperature rise.

In [13], the authors identified that diagnostic tests are a central tool in the fight against the pandemic, these tests are based on antigen-antibody recognition and provide results in several minutes, their main problem is that they are qualitative and only report the presence of antibodies, which indicates an active infection or having passed such infection. Therefore, they proposed to develop a COVID-19 detection system using biosensors based on graphene transistors. The proposed method consists of using biosensors based on graphene transistors to develop a microfluidic chip integrated on a graphene FET sensor array. 


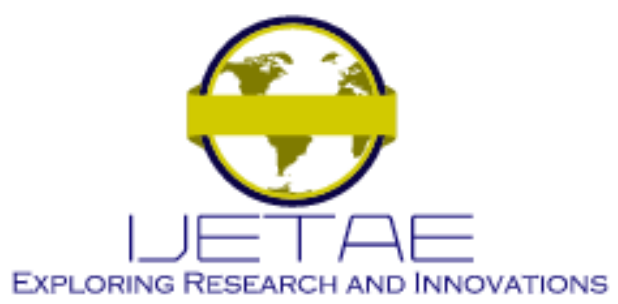

International Journal of Emerging Technology and Advanced Engineering

Website: www.ijetae.com (E-ISSN 2250-2459, Scopus Indexed, ISO 9001:2008 Certified Journal, Volume 11, Issue 09, September 2021)

As a result, a detection efficiency of $96 \%$ was obtained, concluding that the system is easy to use, fast (seconds from sample collection to result) and ultrasensitive to detect immunoglobulins against SARS-CoV-2 S protein.

In [14], the author identified that the arrival of COVID19 brought global health crisis in the mining sector, generating major changes in the digital and technological field, to monitor standards, to foresee potential risks or to optimize processes and reduce risks, entering this industry by leaps and bounds, which is why he developed a security monitoring and prevention measures of COVID-19 contagion through detection in CCTV system for mining. The proposed method consists of using COCO dataset in a CenterNet network architecture to detect people, also used YOLO Darknet for the YOLOv5 network and the use of the Roboflow platform. They obtained as a result an efficiency of $98 \%$, concluding that the system informs about social distancing, the use of masks, helmets, and surveillance of restricted areas in an effective way.

In [15], the author identified that an effective solution for COVID-19 has not yet been found and that only the recommendations of the authorities and health organizations should be followed, which are the use of masks, maintaining two meters of social distance, frequent hand washing, avoiding frequent mouth or nose contact. Of all these measures, social distancing is something that cannot be properly controlled, which is why it was proposed to implement a social distancing recognition system as a preventive measure for COVID-19 using Deep Learning. The proposed method consists of using the object detection model YOLO version 3 trained with the COCO image set, obtaining as a result an accuracy of $80 \%$, concluding that the system correctly detects social distancing, and that Yolo was also very effective in detecting people with quite high scores in each detection.

\section{Methodology}

We designed a thermal imaging system to detect possible cases of COVID-19 patients. We try to find a common symptom of COVID-19, which is fever, for this we will use a set of electronic devices as shown in Figure 1, which allows us to obtain the value of body temperature.

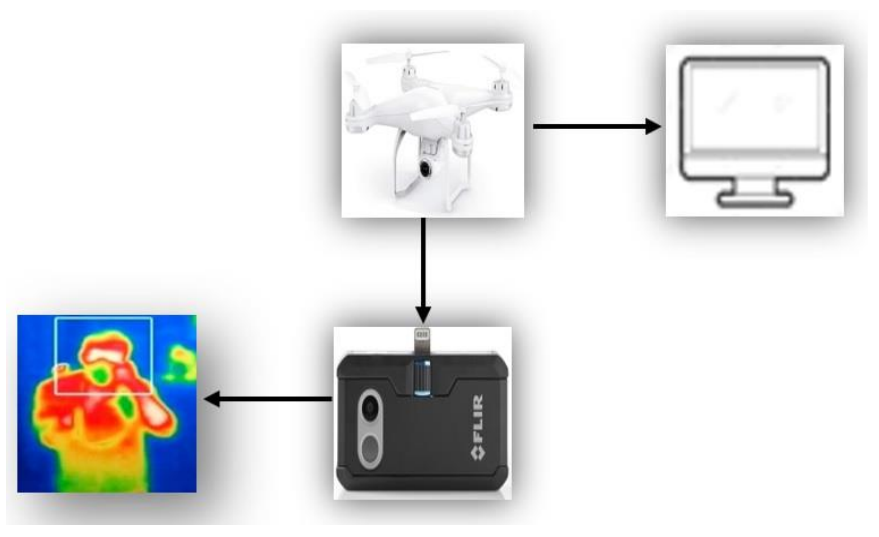

Fig. 1. Thermal Imaging System

The drone will take the photo of the person using a FLIR ONE Pro thermal camera, then that image will be processed by the MATLAB software, with this it will be possible to know the person's body temperature and thus know if it is a COVID-19 patient.

\section{A. Drone Potensic T25}

The electronic part is composed of a potensic T25 drone as shown in Figure 2, which through the thermal camera will take photos of people and thus be able to detect their body temperature. This drone was considered because it has the following characteristics: 1080P FHD camera, it has an adjustable angle of $0-90^{\circ}$, it captures high-quality video and takes aerial photos reaching a height of 300 meters, in addition to having a 3.7V 1000Mah battery [16].

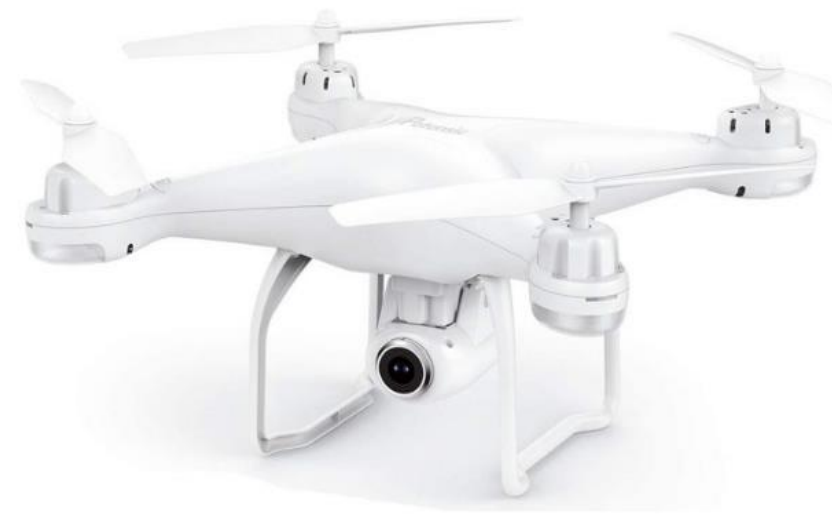

Fig. 2. Drone Potensic T25 


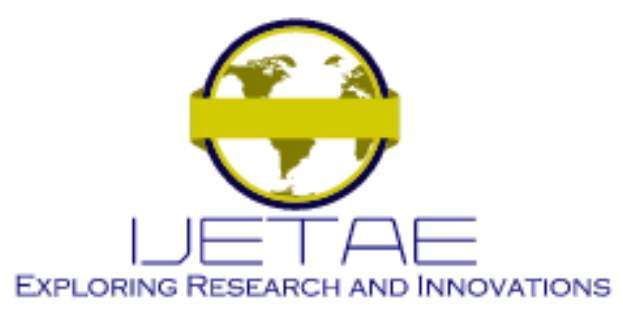

International Journal of Emerging Technology and Advanced Engineering

Website: www.ijetae.com (E-ISSN 2250-2459, Scopus Indexed, ISO 9001:2008 Certified Journal, Volume 11, Issue 09, September 2021)

\section{B. FLIR ONE Pro}

The FLIR ONE Pro is a thermal camera that has 2 lenses as shown in Figure 3, the upper camera lens captures images, and the lower camera lens captures thermal images. This equipment is compatible with Android and IOS mobile devices, so the shape of the connector for a mobile device varies, in addition, it has software that allows processing those received thermal images such as: changing the temperature range, changing the map colors heat and among other things.

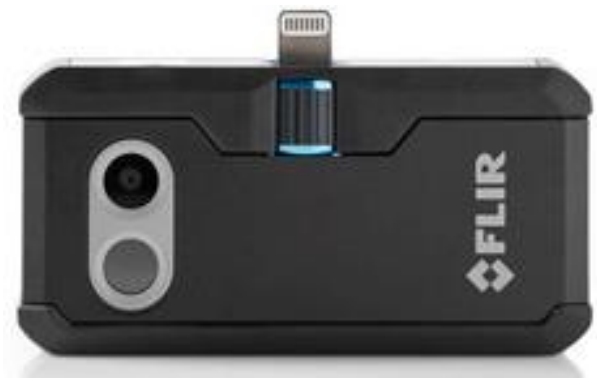

Fig. 3. FLIR ONE Pro Thermal Camera

Table I shows the characteristics of the FLIR ONE Pro thermal camera [17].

Table 1.

Characteristics of the FLIR ONE Pro

\begin{tabular}{|c|c|}
\hline \multicolumn{2}{|c|}{ FLIR ONE Pro } \\
\hline Temperature Range & $-20{ }^{\circ} \mathrm{C}-400{ }^{\circ} \mathrm{C}$ \\
\hline Compatibility & IOS and Android devices \\
\hline Maximum distance & Functional at 1.8 meters \\
\hline Weight & $36.5 \mathrm{~g}$. \\
\hline Dimensions & $68 \times 34 \times 14$ millimeters \\
\hline Thermal Resolution & $160 \times 120$ \\
\hline Operating Time & 1 hora \\
\hline
\end{tabular}

\section{MATLAB}

MATLAB software is a useful tool for performing digital image processing in different professional areas such as medical diagnosis, astronomy, pattern matching and recognition (vehicle license plate recognition, fingerprint and palm recognition) for security applications, forensic analysis, geographic information systems, human computer interfaces, industrial inspection, document processing, remote sensing, satellite image processing, and wireline and wireless image transmissions [18].
Regarding the MATLAB version, the MATLAB R2019b version was used, because it is the version that has more functions than its predecessors. It should be noted that a higher version than the one used in this paper can be used.

The basic picture element is called a pixel, and a $M \times \mathrm{N}$ image has $\mathrm{M}$ rows of pixels and $\mathrm{N}$ columns of pixels. Also, the reader can think of a $2 \mathrm{D}$ grid or matrix whose elements are represented by $\mathrm{f}(\mathrm{x}, \mathrm{y})$, where $\mathrm{x}$ and $\mathrm{y}$ are the coordinates of the grid or the indices of the elements of the matrix [18].

The types of image processing that are applied to an RGB image are, for example: "grayscale", uses different shades of gray in an image. In 8-bit images, there can be up to 256 shades of gray. Each pixel in a grayscale image has a brightness value between 0 (black) and 255 (white) [19]. Another is "binarization", it converts the digital image into a black and white image, in such a way that the essential properties of the image are preserved. One of the methods to be able to binarize a digital image is through the histogram of the image [20]. Another is "pixel mapping", it records an arbitrary number of moving images with respect to the fixed image (reference) [21]. Another is "subtraction of images", it subtracts each element of the matrix from the corresponding element of the matrix and returns the difference in the corresponding element of the output matrix [19].

\section{Body temperature}

Body temperature in people due to COVID-19 is taken when entering establishments such as supermarkets, banks, etc. to prevent the increase in infections. The measurement can be carried out on the forehead or on the part of the wrist and they show normal temperatures that range between $36.1^{\circ} \mathrm{C}$ and $37.2^{\circ} \mathrm{C}$ (degrees Celsius) [22], it should be noted that outside the establishments the measurement of body temperature, so people are not aware of this valuable information.

Most of the people who go to their workplace or to carry out some procedure outside the home, run the risk of becoming infected since they do not know who they could meet on the road, therefore, they must be protected.

The US Centers for Disease Control and Prevention considers a person to have a fever when their temperature is $38^{\circ} \mathrm{C}$ or higher. It can also be determined that people who feel hot or who have a history may have a fever [22], it is a factor to take into account. 


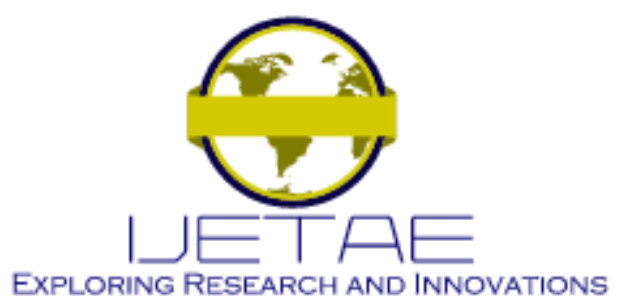

International Journal of Emerging Technology and Advanced Engineering

Website: www.ijetae.com (E-ISSN 2250-2459, Scopus Indexed, ISO 9001:2008 Certified Journal, Volume 11, Issue 09, September 2021)

\section{E. Drone position}

The drone must be at a specific distance, it cannot take any distance, but it should take a distance in the range of 1 to 2 meters, because it is a distance that is recommended as mentioned above.

It should also be considered that when handling the drone, it must have a line of sight, that is, there is no obstacle between the thermal camera and the person, otherwise the corresponding photo cannot be obtained. Figure 4 shows the position in which the drone is in front of the person, pointing clearly at the person's face, specifically at the forehead because it is the point where the temperature sample will be taken at 1 meter per subject of the distance protocol to the person who will be photographed for later analysis with the MATLAB software.

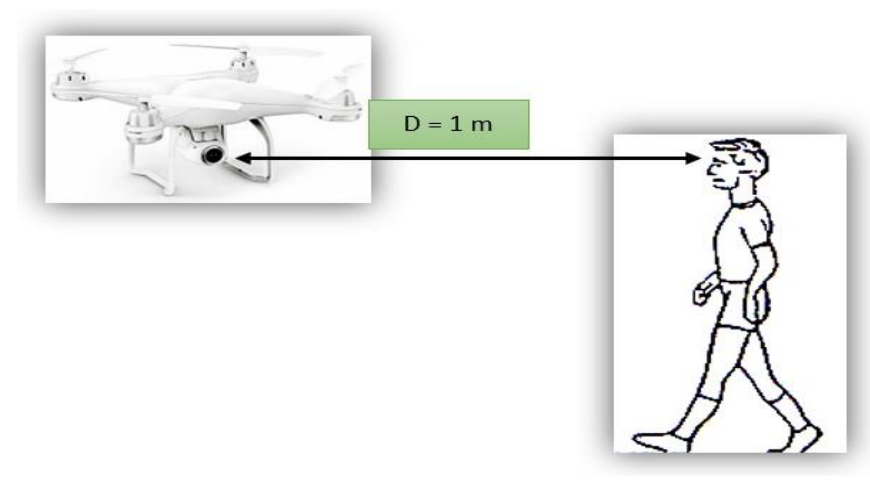

Fig. 4. Distance between the Potensic T25 drone and the person.

The distance in which the drone takes the photo to the person, greatly influences the image quality obtained as seen in Figure 5 and in Figure 6. It is observed that the images obtained are blurred, the further away it is the person, the blurrier the image of the person will be.

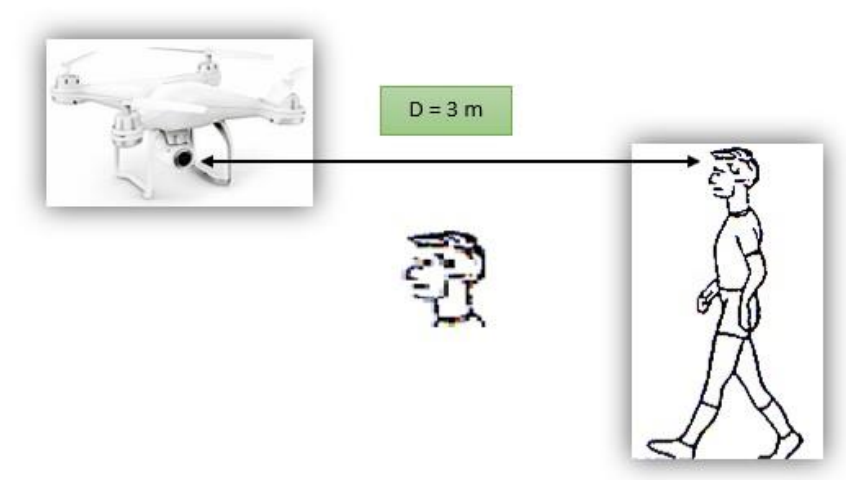

Fig. 5. Distance between the Potensic T25 drone and the person at a distance of 3 meters.

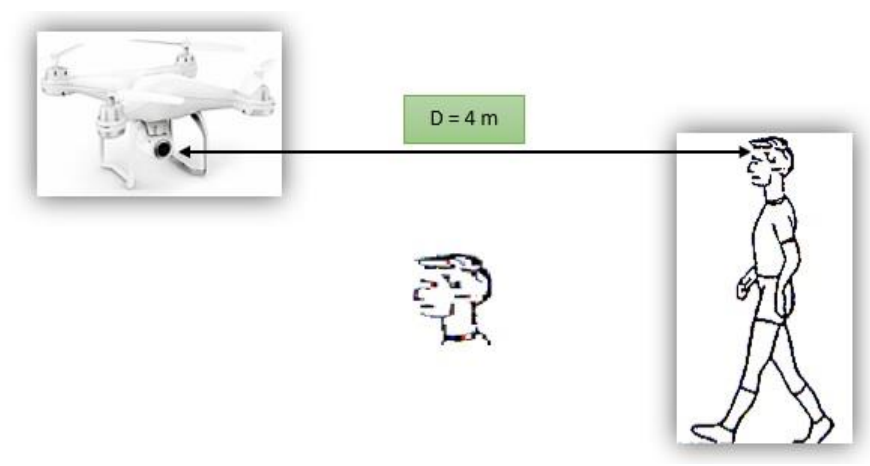

Fig. 6. Distance between the Potensic T25 drone and the person at a distance of 4 meters.

\section{RESULTS}

In this article, a study was developed on the design of a thermal imaging system to detect possible cases of COVID19 patients. With this, the purpose of knowing the body temperature of each worker before entering their workplace would be fulfilled, even of any person whose body temperature is to be measured. Table II shows the characteristics that were considered for the thermal images.

Table 2.

Characteristics of the Thermal Image

\begin{tabular}{|c|c|}
\hline \multicolumn{2}{|c|}{ Thermal Imaging } \\
\hline Distance & $50 \mathrm{~cm}$ \\
\hline Temperature range & $\begin{array}{c}\text { Normal: } 36.1^{\circ} \mathrm{C}-37.2^{\circ} \mathrm{C} \\
\text { Elevated: } 38^{\circ} \mathrm{C} \text { or more }\end{array}$ \\
\hline $\begin{array}{c}\text { Place where the image } \\
\text { was captured }\end{array}$ & Forehead \\
\hline Rest Time & 0 minutes of rest \\
\hline
\end{tabular}

In such a way that if a person has a body temperature higher than $38^{\circ} \mathrm{C}$, they could be infected with COVID-19, as shown in Figure 7. Therefore, this system will be very useful to reduce the number of infections.

The body temperature measurement was performed on the person's forehead, mainly because it is an area that is more exposed to the air and its temperature does not vary unlike another part of the body that is covered by a garment. 


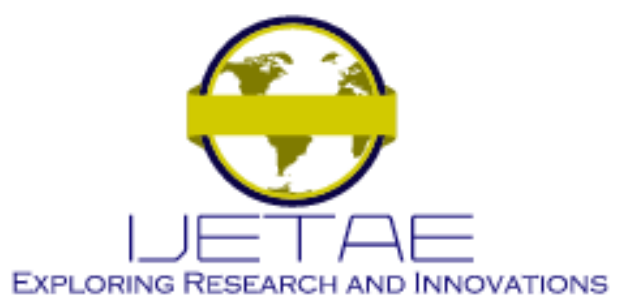

International Journal of Emerging Technology and Advanced Engineering

Website: www.ijetae.com (E-ISSN 2250-2459, Scopus Indexed, ISO 9001:2008 Certified Journal, Volume 11, Issue 09, September 2021)

The distance in which the Potensic T25 drone together with the FLIR ONE Pro thermal camera will be located from the person is $50 \mathrm{~cm}$, since it is a distance in which the thermal camera will capture a good quality of photo and avoid physical damage to the person with the propellers of the drone.

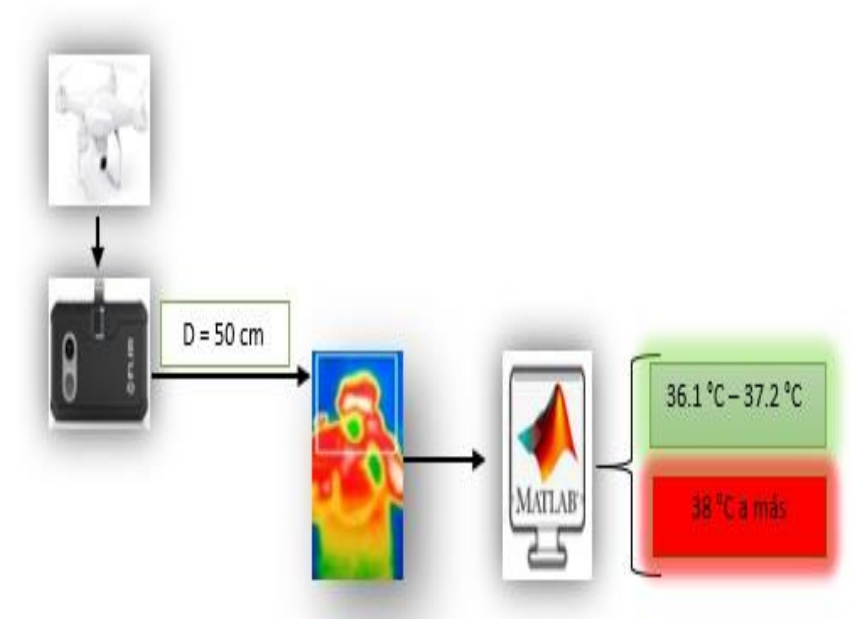

Fig. 7. Thermal image processing system to detect possible cases of patients with COVID-19.

For the implementation of the system, it is necessary to have all the electronic equipment mentioned above and to carry out the programming in MATLAB for image processing. In addition, the mentioned values must be considered, such as the distance between the drone and the person, the characteristic of the drone and the FLIR ONE Pro thermal camera, this will allow an efficient operation of the system.

It should be noted that this system can be used in a university, as it would be of great help to control the temperature of workers more accurately unlike other systems or methods, it is currently observed that to enter a university or a mall only measure the temperature with an infrared thermometer along with the application of alcohol on the hands, so that measure is not so safe.

\section{DISCUSSION}

The articles written about COVID-19 share the same purpose, which is to prevent contagion between people and thus control the spread of the virus that currently continues to plague several countries.
Never before has a research work similar to this research work been carried out, therefore, it differs from many research works, among them we have the work carried out by [10], who propose a system by processing video images to detect if the people respect social distancing. While it is true, they had a result of $92.43 \%$, but this research does not indicate if people can be COVID-19 patients, since they prioritize social distancing.

We also have the research work by [11], who propose a COVID-19 social distancing surveillance system, only this time it will notify authorities if social distancing is being breached. While it is true, they had a result of $90 \%$, but this research work does not indicate the body temperature of people, since they prioritize social distancing.

We also have the research work carried out by [12], who propose a system for detecting the fever of employees with the thermal camera, this research work only measures the body temperature of workers before entering their workplace. Although it is true, they had a result of $99.78 \%$, but this system cannot interact with people outside of their workplace so it would have limited operation.

We also have the research work done by [13], who propose a COVID-19 detection system with biosensors based on graphene transistors, this research work only detects if a person is with COVID-19. While it is true, they had a result of $96 \%$, but this system cannot detect if a person has a temperature variation so it would have a limited performance.

We also have the research work done by [14], who proposed a security monitoring and prevention measures of COVID-19 contagion through detection in CCTV system for mining, this research work only monitors if they comply with safety measures. Although it is true, it had a result of $98 \%$, but this system cannot detect the variation of people's temperature.

We also have the research work done by [15], who proposed to implement a social distancing recognition system as a preventive measure for COVID-19 using Deep Learning, this research work only shows the social distancing between people. While it is true, they had a result of $80 \%$, but this system cannot detect if a person may have a fever.

\section{CONCLUSION AND RECOMMENDATION}

It is concluded that the use of this system has good functionality, this would confirm that its use will help reduce infections between people since it will detect body temperature and give a warning. 


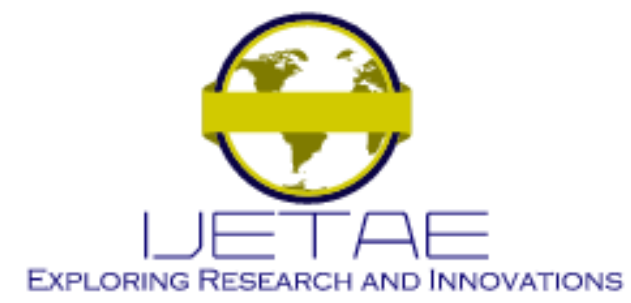

International Journal of Emerging Technology and Advanced Engineering

Website: www.ijetae.com (E-ISSN 2250-2459, Scopus Indexed, ISO 9001:2008 Certified Journal, Volume 11, Issue 09, September 2021)

It is concluded that the use of this system can be used anywhere and with anyone, because it has a drone allowing photos to be taken without the need to get closer to the person.

It is concluded that this system is very safe and reliable because there is no risk of being infected when people interact, since the drone will do it. So, care must be taken when handling the drone.

It is concluded that the use of MATLAB software helps a lot to carry out the image processing for this system, although its programming is more rigid.

As work in the future, the implementation of the system will be carried out and the drone will be used with different people, so this system will serve to help prevent infections that are currently growing. This would prevent the spread of the virus. In addition, it will be tested at the Universidad de Ciencias y Humanidades to students, teachers, and workers.

It is recommended to consider the distance in which the drone will be in front of the person, it cannot be very far since it will not take the photo of good quality, nor very close since it could cause physical damage to the person with the propellers of the drone.

\section{REFERENCES}

[1] M. Adnan Shereen, S. Khan, A. Kazmi, N. Bashir, and R. Siddique, "COVID-19 infection: Emergence, transmission, and characteristics of human coronaviruses,” J. Adv. Res., vol. 24, pp. 91-98, Jul. 2020, doi: 10.1016/j.jare.2020.03.005.

[2] F. Jirjees, Y. Dallal Bashi, and H. Al-Obaidi, "COVID-19 Death and BCG Vaccination Programs Worldwide," Tuberc. Respir. Dis. (Seoul)., vol. 84, no. 1, pp. 13-21, Jan. 2021, doi: 10.4046/TRD.2020.0063.

[3] M. Palacios Cruz, E. Santos, M. Velázquez Cervantes, and M. León Juárez, "COVID-19, a worldwide public health emergency," Rev. Clínica Española (English Ed., vol. 221, no. 1, pp. 55-61, Jan. 2021, doi: 10.1016/j.rceng.2020.03.001.

[4] C. Apaza, R. Seminario Sanz, and J. Santa-Cruz Avéralo, "Factores psicosociales durante el confinamiento por el Covid-19 - Perú," Rev. Venez. Gerenc., vol. 25, 2020.

[5] D. Amsalem, L. Dixon, and Y. Neria, "The Coronavirus Disease 2019 (COVID-19) Outbreak and Mental Health: Current Risks and Recommended Actions," JAMA Psychiatry, vol. 78, no. 1, pp. 9-10, Jan. 2021, doi: 10.1001/jamapsychiatry.2020.1730.

[6] U. Cáceres Bernaola, C. Becerra Núñez, S. Mendívil Tuchía de Tai, and J. Ravelo Hernández, "Primer fallecido por COVID-19 en el Perú," An. la Fac. Med., vol. 81, no. 2, pp. 201-205, Jul. 2020, doi: 10.15381/anales.v81i2.17858.

[7] M. Pérez Abreu, J. Gómez Tejeda, and R. Dieguez Guach, "Características clínico-epidemiológicas de la COVID-19," Rev. Habanera Ciencias Médicas, vol. 19, no. 2, pp. 1-15, Apr. 2020.

[8] C. Maguiña Vargas, "Reflexiones sobre el COVID-19, el Colegio Médico del Perú y la Salud Pública," Acta Médica Peru., vol. 37, no.
1, pp. 8-10, Mar. 2020, doi: 10.35663/amp.2020.371.929.

[9] N. Jones, Z. Qureshi, R. Temple, J. Larwood, T. Greenhalgh, and L. Bourouiba, "Dos metros o uno: ¿cuál es la evidencia del distanciamiento físico en COVID-19?," Aug. 25, 2020.

[10] C. Niño Rondón, S. Castro Casadiego, B. Medina Delgado, D. Guevara Ibarra, and J. Gómez Rojas, "Procesamiento de imágenes de video para verificar el distanciamiento social durante la pandemia de COVID-19," Rev. Logos, Cienc. Tecnol., vol. 13, no. 1, pp. 116127, Dec. 2020, doi: 10.22335/rlct.v13i1.1305.

[11] P. Somaldo, F. Ferdiansyah, G. Jati, and W. Jatmiko, "Developing Smart COVID-19 Social Distancing Surveillance Drone using YOLO Implemented in Robot Operating System simulation environment," 2020 IEEE 8th R10 Humanit. Technol. Conf., pp. 16, Dec. 2020, doi: 10.1109/R10-HTC49770.2020.9357040.

[12] A. Gupta, S. Maurya, N. Mehra, and D. Kapil, "COVID-19: Employee Fever detection with Thermal Camera Integrated with Attendance Management System," Proc. Conflu. 2021 11th Int. Conf. Cloud Comput. Data Sci. Eng., pp. 355-361, Jan. 2021, doi: 10.1109/Confluence51648.2021.9377079.

[13] F. Gámiz et al., "Detección de la COVID-19 con biosensores basados en transistores de grafeno," GranadaEspaña, 57, Sep. 2020.

[14] J. Musso Zapico, "Monitoreo de seguridad y medidas de prevención de contagio de Covid-19 mediante detección en sistema CCTV para la minería," Universidad de Chile, Santiago de Chile - Chile, 2021.

[15] W. S. Córdova Eras, "Implementación de un sistema de reconocimiento de distanciamiento social como medida preventiva para covid 19 usando deep learning," Machala: Universidad Tëcnica de Machala, Machala - Ecuador, 2020.

[16] S. Sudha and S. Nagarajan, "Solar Charged Automated Drones Using Recognition Of The Institution In Zambia," J. Intell. Syst. Robot. Insights Transform., vol. 3, no. 1, 2019.

[17] B. Meneses Claudio, W. Alvarado Díaz, F. Flores Medina, N. Vargas Cuentas, and A. Roman Gonzalez, "Muscles Heating Analysis in Sportspeople to Prevent Muscle Injuries using Thermal Images," IJACSA) Int. J. Adv. Comput. Sci. Appl., vol. 10, no. 6, 2019.

[18] Y. Pallo Jiménez, "Desarrollo de aplicaciones prácticas en la adquisición y procesamiento de imágenes en MatLab y LabVIEW," Universidad Católica de Santiago de Guayaquil, Guayaquil Ecuador, 2021.

[19] R. De Armas Costa, S. Quintero Torres, C. Acosta Muñoz, and C. Rey Torres, "La transformada de Radon aplicada a la segmentación de imágenes digitales en escala de grises," Rev. Ing. Univ. Medellín, vol. 17, no. 32, pp. 213-227, 2018, doi: 10.22395/rium.v17n32a10.

[20] Y. De la Cruz and J. Tinoco, "Determinación de la Calidad de Granos de Arroz Pulido Utilizando Algoritmos de Procesamiento Digital de Imágenes," Universidad Nacional Pedro Ruiz Gallo, Lambayeque - Perú, 2019.

[21] E. Alves and J. Ramos, "Numerical analysis of collapse modes in optimized design of alveolar Steel-concrete composite beams via genetic algorithms," REM - Int. Eng. Journal., vol. 74, no. 2, pp. 173-181, Apr. 2021, doi: 10.1590/0370-44672020740060.

[22] D. Montiel, E. Torres, M. Jarolin, V. Taboada, C. Alderete, and L. Negri, "Thrombotic thrombocytopenic purpura associated with COVID-19," Rev. salud publica del Paraguay, vol. 11, no. 1, pp. 117-120, Jun. 2021, doi: 10.18004/rspp.2021.junio.117. 